\section{Deprivation, distance and death in lung cancer}

\author{
Michael D Peake
}

There are wide differences in survival rates for lung cancer both within the $\mathrm{UK}^{1}$ and when comparing the UK with many countries in the western world. ${ }^{2}$ Socio-economic inequalities have been shown to have a significant impact on survival for the large majority of cancers in adults in the UK, ${ }^{3}$ and many studies have reported lower lung cancer survival rates in patients of lower socio-economic status. ${ }^{4-7}$ There is also wide variation in treatment rates of patients with lung cancer by geographical region, ${ }^{189}$ and the paper by Forrest et $a l^{10}$ in this issue adds to the broadly consistent finding of lower treatment rates in patients from lower socio-economic backgrounds. ${ }^{11}$ In addition, many patients with lung cancer die very soon after diagnosis, a significant proportion with a particularly poor prognosis first presenting to secondary care as an emergency admission, ${ }^{12}$ a route to diagnosis that is more common in patients of lower socio-economic status. ${ }^{13}$ This would imply opportunities for earlier recognition of patients at high risk of lung cancer in primary care. Four important studies appear in this issue of Thorax, three from the UK and one from Australia, that address the issues of earlier diagnosis, early death, undertreatment and geographical distance from specialist centres, all of which have significant implications for optimising service provision for patients with lung cancer. ${ }^{10}$ 14-16

Despite major improvements to cancer care in England over the last 15 years, the 'deprivation gap', in other words, the survival difference between individuals from the least-deprived compared with the mostdeprived groups, has not improved significantly in recent years, ${ }^{17}$ a finding confirmed and startlingly quantified in a recent report from Public Health England's National Cancer Intelligence Network. ${ }^{18}$ This analysis estimated that both incidence and mortality for all cancers combined (excluding non-melanoma skin cancer) were higher in the more-deprived quintiles than the leastdeprived; if rates for the more-deprived groups had been the same as the leastdeprived, around 15300 fewer cancers

Correspondence to Dr Michael D Peake, University Hospitals of Leicester, Glenfield Hospital, Groby Road, Leicester LE3 9QP, UK; mick.peake@uhl-tr.nhs.uk would have been diagnosed per year in the most recent period examined (2006-2010). Similarly, there was a yearly excess of around 19200 deaths from cancer in the period 2007-2011. Lung cancer had, by far, the largest number of excess cases (11 700 persons per year) and deaths (9900 persons per year) in the most recent periods.

The study from Forrest et al ${ }^{10}$ identifies that the dominant factor in the poorer outcomes for more-deprived patients with lung cancer in the Northern and Yorkshire region of England is that they receive lower rates of treatment than their more affluent counterparts. They had postulated that timeliness of treatment from the point of referral from primary care might be a factor, linked to socio-economic status, but were not able to show that. Khakwani et $a l,{ }^{14}$ also in this issue, have demonstrated that lung cancer centres in England with specialist thoracic surgical services have higher resection rates for patients referred directly to them than for those referred from the wider and much larger catchment areas that they serve. Reporting in this issue too, Tracey et $a l,{ }^{15}$ from New South Wales in Australia, found that the further patients live from a specialist thoracic surgical centre, the less likely they are to receive surgical treatment for their lung cancer. In both these studies and others from the UK, the outcomes from larger specialist thoracic surgical centres ${ }^{19}$ with greater number of specialist thoracic surgeons $^{20}{ }^{21}$ were superior to smaller units. Important also is that a clear link between surgical and overall treatment rates and survival at population level has been demonstrated. ${ }^{22} 23$

This is all very pertinent to the debate about the centralisation of cancer services. There is a clear logic in bringing the best available expertise into a smaller number of centres, with the hope and expectation that the care and survival outcomes of patients treated there would improve, but with this centralisation comes increasing geographical distances that are likely to further widen this deprivation gap. Studies in several cancers have shown that geographical distance from specialist centre and the related transport issues are associated with lower treatment rates and poorer outcomes. ${ }^{24} 25$ One such study elegantly demonstrated that, for patients with lung cancer in the Yorkshire region of England, while increased level of deprivation and longer distance from the specialist centre were each independently associated with lower radical treatment rates, for the most-deprived group who also lived the most distant from the treatment centres, the ORs of receiving treatment were very much worse at 0.6 for surgical resection and 0.55 for any active treatment. $^{26}$ The distances and travel times involved in the UK are dwarfed by comparison with some other parts of the world; Tracey et $a l^{15}$ grouped travel distances to a specialist centre in New South Wales as 0-39 km, 40-99 km and $\geq 100 \mathrm{~km}$, posing much greater logistic problems. All these issues are likely to have a disproportionately adverse impact on the care of older patients for whom travel is more problematic.

Such geographical and socio-economic factors could well be part of the explanation for the lower surgical rates demonstrated by Khakwani et $a l^{14}$ for the very much more widely spread populations served by larger thoracic surgical centres, although the authors suggest that the explanation might lie in referral practices and service configuration. In the UK, most patients with lung cancer are managed by multidisciplinary teams (MDTs) in District General Hospitals and referred on to larger centres for radical treatment, particularly surgery. While thoracic surgeons do attend these local MDTs, evidence suggests that there are still some patients who might have been considered suitable for radical therapy when discussed at a larger, more specialised MDT, who are being denied these treatments. ${ }^{20} 2127$

Looking at the characteristics of patients seen in primary care that are associated with early death from lung cancer, O'Dowd et $a l^{16}$ identified low socioeconomic status and 'rurality' with a risk of early death (multivariate ORs 1.16 and 1.22, respectively), which would be entirely consistent with the importance of deprivation and distance from major (urban) specialist centres. They also showed that, paradoxically, patients who died early after diagnosis had attended their general practitioners (GPs) more often, suggesting that there were missed opportunities for earlier referral.

This plethora of recent inter-related research needs to be heeded by those responsible for the commissioning and delivery of lung cancer services and by those concerned with the public health aspects of healthcare delivery. O'Dowd's paper $^{16}$ points to the likelihood of missed 
opportunities for earlier diagnosis in primary care and suggests that better clinical decision aids would be worth investigating. The aim of the government's 'Be Clear on Cancer' campaigns raising public awareness of persistent cough as an early symptom of lung cancer ${ }^{28}$ is to promote earlier presentation to GPs and has tried to target social grades C2, D and E. However, efforts to improve the care for the more deprived are not without their unintended consequences. As long ago as 1971 Tudor Hart described what he called the Inverse Care Law-that 'the availability of good quality health care is inversely related to need in the population served'. ${ }^{29}$ In Dr Forrest's paper, ${ }^{10}$ she refers to work by White et $a l^{30}$ who have described the phenomenon of intervention-generated inequalities, where such things as measures to increase public awareness, promote early presentation and partake of screening programmes are likely to be more actively taken up by people in higher socio-economic status. So while such interventions may improve the health outcomes of the population as a whole, the 'deprivation gap' only widens.

In summary, there is overwhelming evidence that patients with lung cancer of lower socio-economic status receive less treatment and have poorer short-term and long-term survival outcomes compared with their more affluent counterparts. The number of excess deaths linked to deprivation is large and the gap between the least and most deprived has not lessened over time. Improved targeting of public awareness campaigns to specific social groups is important so as not to widen this gap even further. Better ways of supporting clinicians in primary care in their difficult task of identifying very high-risk patients to refer for specialist assessment need to be developed and should probably include more accurate clinical decision support tools. Travel times and the availability of public transport need to be taken into account when decisions are being made about service configuration. Every patient should have access to the most expert of multidisciplinary opinion, but clearly the number of highly specialised centres has to be limited, so much more effective hub-andspoke relationships need to be developed to make decision making as consistent and effective as possible. It has to be our aim to find ways of ensuring equitable access to the highest quality of care for all patients with lung cancer wherever they live and whatever their social background.
Competing interests None.

Provenance and peer review Not commissioned; internally peer reviewed.

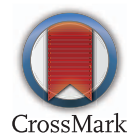

To cite Peake MD. Thorax 2015;70:108-109.

Published Online First 13 October 2014

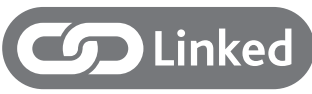

- http://dx.doi.org/10.1136/thoraxjnl-2014-205517

- http://dx.doi.org/10.1136/thoraxjnl-2014-205554

- http://dx.doi.org/10.1136/thoraxjnl-2014-205841

- http://dx.doi.org/10.1136/thoraxjnl-2014-205692

Thorax 2015;70:108-109.

doi:10.1136/thoraxjnl-2014-206153

\section{REFERENCES}

1 NHS Information Centre. National Lung Cancer Audit Report 2013. Leeds: NHS InformationCentre for Health and Social Care, 2013. https://catalogue.ic. nhs.uk/publications/clinical/lung/nati-clin-audi-suppprog-lung-canc-coho-2012/clin-audi-supp-prog-lungnlca-2013-rep.pdf (accessed 8 Jun 2014).

2 De Angelis R, Sant M, Coleman MP, et al. Cancer survival in Europe 1999-2007 by country and age: results of EUROCARE-5—a population-based study. Lancet Oncol 2014;15:23-34.

3 Coleman MP, Babb P, Damiecki P, et al. Cancer Survival Trends in England and Wales 1971-1995: Deprivation and NHS Region. (Studies on Medical and Population Subjects No. 61). London: The Stationery Office, 1999.

4 Riaz SP, Horton M, Kang J, et al. Lung cancer incidence and survival in England: an analysis by socioeconomic deprivation and urbanization. J Thorac Oncol 2011:1:1.

5 Coleman MP, Rachet B, Woods LM, et al. Trends and socioeconomic inequalities in cancer survival in England and Wales up to 2001. Br I Cancer 2004:90:1367.

6 Berglund A, Lambe M, Lüchtenborg M, et al. Social differences in lung cancer management and survival in South East England: a cohort study. Br Med J Open 2012;2:pii: e001048.

7 Jack RH, Gulliford MC, Ferguson J, et al. Geographical inequalities in lung cancer management and survival in South East England: evidence of variation in access to oncology services? Br J Cancer 2003;88:1025.

8 Imperatori A, Harrison RN, Leitch DN, et al. Lung cancer in Teesside (UK) and Varese (Italy): a comparison of management and survival. Thorax 2006;61:232-9.

9 Myrdal G, Lamberg K, Lambe M, et al. Regional differences in treatment and outcome in non-small cell lung cancer: a population-based study (Sweden). Lung Cancer 2009;63:16-22.

10 Forrest L, Adams J, Rubin G, et al. The role of receipt and timeliness of treatment in socio-economic inequalities in lung cancer survival: populationbased, data-linkage study. Thorax 2015;70:138-45.

11 Berglund A, Holberg L, Tishelman C, et al. Social inequalities in non-small cell lung cancer management and survival: a population-based study in central Sweden. Thorax 2010;65:327e333.

12 Elliss-Brookes L, McPhail S, Ives A, et al. Routes to diagnosis for cancer-determining the patient journey using multiple routine data sets. $\mathrm{Br} J$ Cancer 2012;107:1220-6.

13 McPhail S, Elliss-Brookes L, Shelton J, et al. Emergency presentation of cancer and short-term mortality. Br J Cancer 2014;109:2027-34.

14 Khakwani $A$, Rich $A$, Powell $H$, et al. The impact of the 'hub and spoke' model of care for lung cancer and equitable access to surgery. Thorax 2015;70:146-51.

15 Tracey E, McCaughan B, Badgery-Parker T, et al. Survival of Australian lung cancer patients and the impact of distance from and attendance at a thoracic specialist centre: a data linkage study. Thorax 2015;70:152-60.

16 O'Dowd E, McKeever T, Baldwin D, et al. What characteristics of primary care and patients are associated with early death from lung cancer in the United Kingdom? Thorax 2015;70:161-8.

17 Rachet B, Ellis L, Maringe C, et al. Socioeconomic inequalities in cancer survival in England after the NHS cancer plan. Br J Cancer 2010;103:446-53.

18 The National Cancer Intelligence Network. Cancer by Deprivation in England, Incidence, 1996-2010, Mortality, 1997-2011. National Cancer Intelligence Network, London, 2014. http://www.ncin.org.uk/ about_ncin/cancer_by_deprivation_in_england (accessed 8 Jun 2104)

19 Lüchtenborg M, Riaz S, Coupland VH, et al. High procedure volume is strongly associated with improved survival after lung cancer surgery. I Clin Oncol 2013;31:3141-6.

20 Lau KK, Rathinam S, Waller DA, et al. The effects of increased provision of Thoracic Surgical specialists on the variation in lung cancer resection rate in England. J Thoracic Oncol 2013;8:68-72.

21 Rich $\mathrm{AL}$, Tata $\mathrm{L}$, Free $\mathrm{CM}$, et al. Inequalities in outcomes for non-small cell lung cancer: the influence of clinical characteristics and features of the local lung cancer service. Thorax 2011;66:1078-84.

22 Cartman ML, Hatfield AC, Muers MF, et al. Lung cancer: district active treatment rates affect survival. J Epidemiol Community Health 2002;56:424-9.

23 Riaz SP, Lüchtenborg M, Jack R, et al. Variation in radical resection for lung cancer in relation to survival: population-based study in England 2004-2006. Eur I Cancer 2012;48:54-60.

24 Jones AP, Haynes R, Sauerzapf V, et al. Travel time to hospital and treatment for breast, colon, rectum, lung, ovary and prostate cancer. Eur $J$ Cancer 2008;44:992-9.

25 Sauerzapf VA, Jones AP, Haynes R, et al. Travel time to radiotherapy and uptake of breast-conserving surgery for early stage cancer in Northern England. Health Place 2008;14:424-33.

26 Crawford SM, Sauerzapf V, Haynes R, et al. Social and geographical factors affecting access to treatment of lung cancer. Br J Cancer 2009;101:897-901.

27 Rich AL, Tata LJ, Free CM, et al. How do patient and hospital features influence outcomes in small cell lung cancer in England? Br. J Cancer 2011;105: 746-52.

28 Be Clear on Cancer Lung Cancer campaign. Public Health England. Press release. https://www.gov.uk/ government/news/dont-ignore-a-persistent-coughwarns-lung-cancer-campaign (accessed 31 Jul 2014).

29 Tudor Hart J. The inverse care law. Lancet 1971;297:405.

30 White M, Adams J, Heywood P. How and why do interventions that increase health overall widen inequalities within populations? In: Babones S, ed. Health, inequality and society. Bristol: Policy Press, 2009:65-83. 